\title{
YIELD RISK AND THE POTENTIAL FOR INSURANCE IN AGRICULTURE
}

\author{
Maire Nurmet ${ }^{1,}$ PhD, associated professor; Katrin Lemsalu' ${ }^{1,} \mathrm{MSc}, \mathrm{PhD}$ student; \\ Anne Poder ${ }^{1,} \mathrm{PhD}$, researcher \\ ${ }^{1}$ Institute of Economics and Social Sciences, Estonian University of Life-Sciences
}

\begin{abstract}
The introduction of yield insurance schemes for the farmers that would contribute to the diversification of risk transfer opportunities in the agricultural sector is under the consideration in Estonia. The paper focuses on agricultural insurance practices that could lead to the solutions for farmers. The aim is to study possible volume of yield insurance in Estonia. The development of agricultural insurance schemes is heterogeneous in different EU Member States and the characteristics of specific agricultural insurances for the crop sector vary from market-based single and combined risk insurances to the policy-type insurances. The analysis of Estonian data indicate that cereal yields and yield volatility differ across the Estonia regions, and the potential market volume for crop insurance is low.
\end{abstract}

Key words: yield insurance, field crops, cereal yield, agro-food sector.

JEL code: Q10, Q18, M48

\section{Introduction}

The agro-food sector is subject to many uncertainties. Risk taking is inevitable and thus income stability and risk balancing are the crucial questions in agriculture. Risk sources influence directly the income of the agro-food enterprises and have an impact on their long-term economic performance. The production in agro-food sector is dependent of factors that are uncontrollable by the farmer, including the agro-climatic conditions, and diseases. Climate change, greater price volatility for inputs and outputs, international trade restrictions, new food safety standards, and EU agricultural policy changes have influence on the income of the farms.

Risk management policies in the EU deal with farm income variability. Research by Cordier (2014) indicates that the respective weight of instruments in the EU policies are $1 \%$ insurance, $39 \%$ safety nets, $60 \%$ income support with direct payments. The proportions of the three types of instruments contribute to farmers' risk management strategies. The support to enhance crop insurance according to Article 37 of the Regulation (EU) n $1305 / 2013$ (rural development policy) has been implemented by few European countries. The problem is that effective EU spending for supporting crop insurance is very limited. High systemic risks, high loss expertise costs and demand of public or subsidized reinsurance limit the development of such instruments (Cordier, 2014). If the CAP budget for the next financial period will be decreased and the available financial resources are scarce, the involvement of the private sector can ensure the development of agro-food sector risk management. There is a discussion in the EU on the role of policy measures and the development of the corresponding market.

The motivation to estimate the possible volume of yield insurance coverage in Estonia comes from the fact that the agricultural insurance availability in Estonia is poor. This issue became especially relevant due to the difficult situation with field crops in 2017, when only approximately $70 \%$ of crops were harvested (SOE, 2018). The introduction of yield and income insurance schemes for the farmers would contribute to the diversification of risk transfer opportunities in the agricultural sector.

The present paper focuses on the research question of what is the potential for implementation of agricultural insurance protection for Estonian farmers. The aim of the present paper is to study the agricultural insurance practices and to estimate the possible volume of yield insurance in Estonia. This will contribute to the discussion on the possible solutions for farmers in a small country where the development of agricultural insurance system is still in progress. 
Agricultural insurance, used by the farmers is a transfer strategy of risk management. Risk transfer strategy means that the consequences of risk incidences will be transferred to other institutions. Typical instruments are fire insurance, crop insurance, weather derivatives, and the use of commodity futures exchanges (Schaper et al., 2009). In the present research, yield insurance is defined as the type of policy that covers yield losses for a given crop due to any meteorological event (Bielza Diaz-Caneja et al., 2009).

The data are collected from the Estonian Statistical Office's database of agricultural production (SOE, 2018). The research uses yield indicators of field crops from 2006- 2016 and includes average yields of cereals by county and year. For the study of the volume of the insurance coverage, cereals yield and yield volatility by county are analysed. The literature review, descriptive analysis method, analysis and synthesis, and graphical analysis are used in order to perform the study.

In order to perform the analysis, the following research tasks have been set: first, analyse the peculiarities of risk transfer strategies via insurance in agriculture. Second, describe the cereal crop yields from 2004 to 2016 by counties total, using statistics on crop yields, and then to compare the differences in average yields by counties and to calculate the potential size of the insurance coverage on the cereals crop yield. Finally, conclusions are given.

\section{Agricultural insurance for agricultural risk management}

The risk management tools in agriculture can be divided into two main groups: strategies concerning on-farm measures and risk sharing strategies. Risk sharing strategies include production contracts, marketing contracts, hedging on future markets, which are tools mainly for price risks mitigation; or participation in mutual funds and insurances, which mitigate mainly production risks. Insurance is an option for risk-transfer among other strategies like marketing contracts, production contracts, hedging on future markets, participation in mutual funds (Meuwissen et al., 1999; Bielza Diaz-Caneja et al., 2009). Figure 1 illustrates different insurance schemes used to hedge production risks (Figure 1). The characteristics of specific agricultural insurances are different in the crop sector and in the livestock sector. Livestock insurance covers mainly non-epidemic diseases and accidents. In crop sector, one of the main strategies for transferring risk is crop insurance (Valverde Arias et al., 2018). European Commission (2006) overview on the insurance schemes describes the hail insurance that can include other scatted risks as fire as most widely extended crop insurance in EU. Some insurance policies address also the risk of frost or a limited number of meteorological events. These are combined risk insurances.

Yield insurance is the type of policy that covers yield losses for a given crop due to any meteorological event. The meteorological origin of the damage has to be identifiable. Yield insurance triggers payoffs when yield falls short of a predetermined level, which is usually based on a historical yield average. In general, all the fields of a farm with the same crop are insured. A yield reduction of one crop will not be compensated if the total production reduction of the farm does not reach the trigger (Bielza Diaz-Caneja, et al., 2009; Du, et al., 2017). Revenue insurance is the combination of yield and price insurance; it takes into account the total value of the production, and the costs of production and it is paid out when revenue falls short of a predetermined level. Predetermined revenue is the product of average yield and a price established in an insurance plan in a given year (Bielza Diaz-Caneja et al., 2009; Du et al., 2017). 


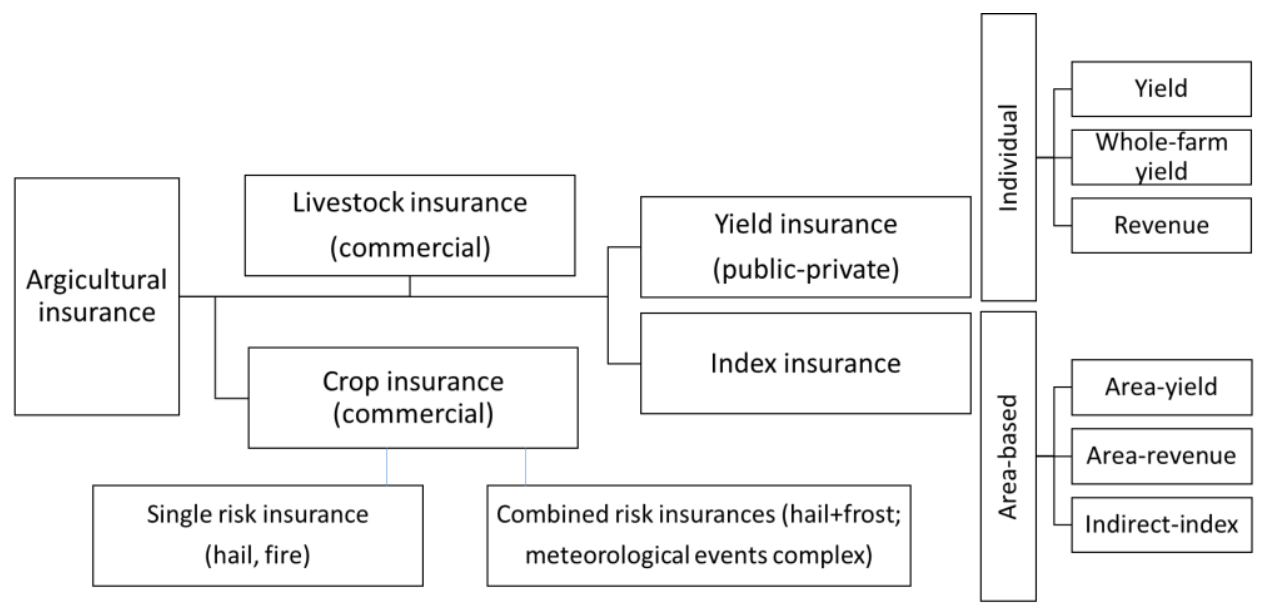

Source: authors' construction based on Bielza Diaz-Caneja, et al., 2009

Fig. 1. Agricultural insurance typology

Bielza Diaz-Caneja et al. (2009) explain that index insurances are based on a common index for an area. In area-yield insurance, the compensation paid to the farmer depends on the statistical yield for the year in a predefined area that is usually an administrative unit. The elements of arearevenue insurance include the area yield multiplied by the area price. All of the farmers in the area who have insured for that crop, get compensation if the average yield/revenue in that area is below a certain threshold. Indirect-index insurance does not refer to the average yield in an area but to a meteorological indicator (Bielza Diaz-Caneja et al., 2009). All of these field-crop insurances rely on information about crop yield, crop production of a certain area, and cover potential loss on these crops in a particular year. The volatility of yields in a particular year compared to years' average serves as the basis for calculations.

The agricultural insurance schemes are very different in the EU Member States. Combined risk insurance is public and compulsory in Greece and Cyprus; private and partially subsidised in Portugal, the Czech Republic, Slovakia, and Romania; and completely private in the Baltic States, Hungary and Bulgaria. Yield insurances guarantee the main risks affecting production, include systemic risks such as drought, and are available in a private partially subsidised system in Spain, Italy, Austria and France (Enjolras et al., 2012). Austria, France, Greece, Italy, the Netherlands and Spain provide crop insurances as safety nets for farmers. These countries have developed crop insurance schemes, which is mostly a combination of public and private partnership. Crop insurances are non-existent in Finland, and despite the growing interest towards agricultural risk management schemes in the EU, the success of existing programs has remained limited (Liesivaara and Muura, 2017). In practice, agricultural insurance has been a costly way of transferring the risk from farmers to governments and other insurers (Nelson and Loehman, 1987). The role of policy measures and the development of the corresponding market is an ongoing discussion in the EU. The farmers' preferences, the perception of risks, farm and farmer characteristics influence the demand for agricultural insurance (Van Asseldonk, et al., 2016). Agricultural insurance captures many different options for the insurable object and it can include both private and public partnership, but, as farm level studies show, the popularity of crop insurance varies considerably across EU Member States. 


\section{Research results}

Insurance products' availability regarding crop losses is very limited in Estonia. The competition between insurance providers is low because the potential market for crop insurance is small and is not economically feasible (IESS, 2016). Crop insurance is suitable for insuring the yield of cereals (barley, oats and wheat) and industrial crops (oilseed rape) and its purpose is to cover losses from adverse weather conditions. Elements for cereal yield insurance administration come from classification of areas under cereals according to their productivity, flow data of cereal productivity in years by economic entities, by regions or the whole country. In context of insurance, the yield in cereal production is determined according to the data on yield loss. Yield loss cost for insurer is equal to indemnity divided by liability, and actuarially fair premium rate is the expected loss cost. The loss cost can be determined by using yield data as a measure of productivity, which is dependent of crop, region, agro-tech production practices, varieties. There are differences in yield risk for different crops, and regions.

The data of SOE (2018) show that the cereals' yield, measured by counties total, has increased during the period from 2004 to 2016 (Fig. 1). In 2017, the average cereal yield per hectare was $3967 \mathrm{~kg}$. The yields of wheat, barley, and oats were accordingly 4202; 4154; and $3932 \mathrm{~kg}$ per hectare in 2017 . The sown area of potatoes were 5400 hectares, and average yield was $16925 \mathrm{~kg}$ per hectare.

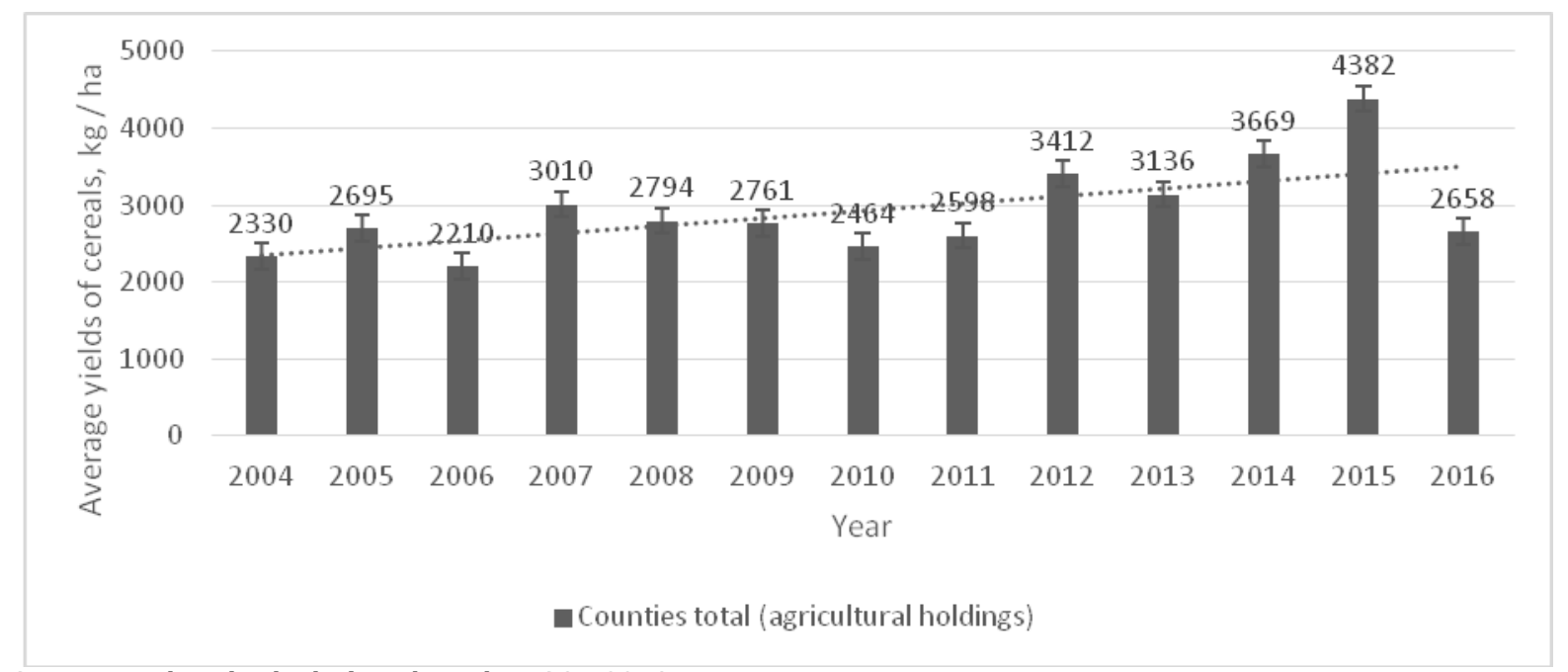

Source: authors' calculations based on SOE 2018

\section{Fig. 2. Average yields of cereals 2004-2016}

The European Union CAP Implementation Act sets out the ground and procedure for implementation of the measures of the common agricultural policy of the European Union, but it does not regulate directly compensation mechanisms regarding crop losses arising from natural disasters. Rural Development and Agricultural Market Regulation Act regulates that the state may grant agricultural insurance support via the Ministry of Rural Affairs or the Estonian Agricultural Registers and Information Board, ARIB (IESS, 2017). The farmers have the right for government subsidies on agricultural insurance in Estonia. According to the terms of agricultural insurance subsidies, the costs for insurance policy are compensated partly for insurance that covers the risk of unfavourable meteorological events as frost, storm, hail, ice etc. The amount of the damage is in extent that destroys more than $30 \%$ of average annual production, calculated as the average of three previous years' annual production. 
The average cereal yield varies across the counties in Estonia. Calculations of cereal yield on the data regarding the average cereal productivity in counties and counties total between 2004 and 2016 were combined. Cereal yield ratio, expressing counties' average differences from the counties total average of last three years is calculated:

$$
\text { cereal yield ratio }=\frac{y_{i j}}{\frac{y t_{i}+y t_{i-1}+\cdots+y t_{i-n}}{n}}
$$

Where $y_{i j}$ is the cereal yield in year $i$ in county $j ; y t_{i}, y t_{i-1}$, and $y t_{i-n}$ are counties' total average yields in years $i, i-1$, and $i-n$, respectively; and $n$ is the number of observable years. The results of calculations are in Table 1.

Cereal yields ratio by county to average total yields of cereals 2004-2016

Table 1

\begin{tabular}{|c|c|c|c|c|c|c|c|c|c|c|c|}
\hline & 2006 & 2007 & 2008 & 2009 & 2010 & 2011 & 2012 & 2013 & 2014 & 2015 & 2016 \\
\hline Harju county & $-20 \%$ & $10 \%$ & $15 \%$ & $7 \%$ & $-11 \%$ & $-2 \%$ & $8 \%$ & $6 \%$ & $8 \%$ & $21 \%$ & $-24 \%$ \\
\hline Hiiu county & $-52 \%$ & $8 \%$ & $-27 \%$ & $-32 \%$ & $-28 \%$ & $-63 \%$ & $-31 \%$ & $-36 \%$ & $-44 \%$ & $-10 \%$ & $-68 \%$ \\
\hline Ida-Viru county & $-6 \%$ & $-6 \%$ & $-8 \%$ & $-3 \%$ & $-12 \%$ & $-3 \%$ & $16 \%$ & $4 \%$ & $7 \%$ & $6 \%$ & $-27 \%$ \\
\hline Jogeva county & $-4 \%$ & $17 \%$ & $5 \%$ & $11 \%$ & $6 \%$ & $8 \%$ & $42 \%$ & $14 \%$ & $16 \%$ & $31 \%$ & $-14 \%$ \\
\hline Jarva county & $-17 \%$ & $-6 \%$ & $1 \%$ & $-10 \%$ & $-7 \%$ & $-1 \%$ & $20 \%$ & $8 \%$ & $6 \%$ & $23 \%$ & $-23 \%$ \\
\hline Laane county & $-21 \%$ & $-8 \%$ & $-13 \%$ & $-12 \%$ & $-29 \%$ & $-25 \%$ & $1 \%$ & $-22 \%$ & $-18 \%$ & $9 \%$ & $-26 \%$ \\
\hline Laane-Viru county & $-16 \%$ & $21 \%$ & $10 \%$ & $0 \%$ & $-1 \%$ & $1 \%$ & $29 \%$ & $15 \%$ & $19 \%$ & $25 \%$ & $-25 \%$ \\
\hline Polva county & $-10 \%$ & $22 \%$ & $11 \%$ & $0 \%$ & $-16 \%$ & $-3 \%$ & $17 \%$ & $-2 \%$ & $12 \%$ & $20 \%$ & $-21 \%$ \\
\hline Parnu county & $-12 \%$ & $-6 \%$ & $-12 \%$ & $-23 \%$ & $-23 \%$ & $-19 \%$ & $-5 \%$ & $-17 \%$ & $-6 \%$ & $-2 \%$ & $-30 \%$ \\
\hline Rapla county & $-11 \%$ & $2 \%$ & $-4 \%$ & $-7 \%$ & $-13 \%$ & $-7 \%$ & $0 \%$ & $-10 \%$ & $8 \%$ & $13 \%$ & $-20 \%$ \\
\hline Saare county & $-40 \%$ & $-13 \%$ & $-20 \%$ & $-22 \%$ & $-28 \%$ & $-25 \%$ & $-7 \%$ & $-14 \%$ & $-11 \%$ & $3 \%$ & $-15 \%$ \\
\hline Tartu county & $17 \%$ & $41 \%$ & $25 \%$ & $7 \%$ & $7 \%$ & $13 \%$ & $41 \%$ & $10 \%$ & $19 \%$ & $22 \%$ & $-30 \%$ \\
\hline Valga county & $10 \%$ & $27 \%$ & $1 \%$ & $-3 \%$ & $-12 \%$ & $9 \%$ & $15 \%$ & $2 \%$ & $-6 \%$ & $9 \%$ & $-29 \%$ \\
\hline Viljandi county & $-8 \%$ & $19 \%$ & $6 \%$ & $-5 \%$ & $-8 \%$ & $7 \%$ & $22 \%$ & $6 \%$ & $7 \%$ & $18 \%$ & $-27 \%$ \\
\hline Voru county & $-14 \%$ & $12 \%$ & $-3 \%$ & $-12 \%$ & $-18 \%$ & $-2 \%$ & $16 \%$ & $-8 \%$ & $-6 \%$ & $6 \%$ & $-43 \%$ \\
\hline
\end{tabular}

Source: author's calculations based on SOE 2018

According to the statistical data about the cereal yields, the lowest average yields in period 2004 - 2016 were in Saare, Hiiu, Parnu and Laane counties. The highest average yields were in Tartu, Valga, Jogeva, Laane-Viru, and Rapla counties. The most volatile cereal yields were in Hiiu, Saare, Valga and Tartu counties, and the most stabile cereal yields were in Viljandi, Parnu, LaaneViru and Polva counties. The counties classified into categories according to cereal yields and yield volatility (Table 2 ).

Table 2

Classification of counties according to cereal productivity and yield volatility

\begin{tabular}{|l|l|l|}
\hline \multicolumn{1}{|c|}{ Category } & \multicolumn{1}{|c|}{ Cereal productivity (yield) } & \multicolumn{1}{c|}{ Cereal yield volatility } \\
\hline Low & Saare, Hiiu, Parnu, Laane & Viljandi, Parnu, Laane-Viru, Polva \\
\hline Average & Harju, Ida-Viru, Jarva, Polva, Viljandi, Voru & Harju, Ida-Viru, Jogeva, Jarva, Laane, Rapla, Vou \\
\hline High & Tartu, Valga, Jogeva, Laane-Viru, Rapla & Hiiu, Saare, Valga, Tartu \\
\hline
\end{tabular}

Source: author's calculations based on SOE 2018

The potential for yield insurance market is measured according to the volume of the mainly grown cultures, cereals. The size of insurance coverage in cereal yield insurance is calculated on the indicators of the average cereal production and average cereal price. According to the data of SOE (2018) the production of cereals in 2017 was more than 1.3 millions of tons, of which 713300 
tons of wheat, 425700 tons of barley and 52400 of rye. The estimated production volume was more than 167 million euros. If insurance coverage is $70 \%$, the potential market volume is estimably 117 million euros. If premium rate is $7 \%$, the maximum potential market volume is 8,9 million euros. The prerequisite of this volume would be compulsory yield insurance to all cereal producers for all cereal crops, which is not achievable in reality. Previous practice from years 20032008 shows that the cereal crop insurance covered approximately $5 \%$ sown area. In case if the participation will stay in a voluntary basis, the potential market volume would stay remarkably lower.

\section{Conclusions}

The agricultural insurance practices study and estimation of possible volume of yield insurance coverage in Estonia results as follows.

1) The characteristics of specific agricultural insurances for the crop sector vary from market-based single and combined risk insurances to the policy-type insurances as yield insurance, wholefarm yield insurance, revenue insurance. Experiences of EU Member States that have implemented the agricultural insurance show that it is successful only if through precise ex-ante evaluation is made, and if the target group is identified and policy developments are well designed.

2) The crop insurance covers the losses of cereals' and industrial crops' yield from adverse weather conditions. The elements for cereal yield insurance administration, includes classification of areas under cereals according to their productivity by regions. Taking into account the differences in yields in cereal production, the counties classified into categories according to cereal yields and yield volatility.

3) The potential crop insurance market volume is relatively low in Estonia.

4) The limitation of the present analysis was the availability of the specific data. The future research would continue with the study on enterprise-level, it would be important to analyse if this indicator shows signs of decrease or increase.

\section{Bibliography}

1. Bielza Diaz-Caneja, M., Conte, C.G., Gallego Pinilla, F.J., Stroblmair, J., Catenaro, R., Dittmann, C. (2009). Risk Management and Agricultural Insurance Schemes in Europe. Luxembourg: Office for Official Publications of the European Communities. 2009 - 30 pp.

2. Cordier, J. (2014). Comparative Analysis of Risk Management Tools Supported by the 2014 US Farm Bill and the CAP 2014-2020. EU Publications Retrieved:

http://www.europarl.europa.eu/thinktank/en/document.html?reference=IPOL_STU(2014)540343 Access: 18.01 .18

3. Du, X., Feng, H., Hennessy, D. A. (2017). Rationality of Choices in Subsidized Crop Insurance Markets. American Journal of Agricultural Economics, Volume 99, Issue 3, pp. 732-756, https://doi.org/10.1093/ajae/aaw035

4. Enjolras, G., Capitanio, F., Adinolfi, F. (2012). The Demand for Crop Insurance: Combined Approaches for France and Italy. Agricultural Economic Review, Volume 13, Issue 1, pp. 5-22.

5. European Commission (2006). Agricultural Insurance Schemes. Summary report. https://ec.europa.eu/agriculture/sites/agriculture/files/external-studies/2006/insurance/summary_en.pdf

6. IESS. Institute of Economics and Social Sciences. (2016). Alternatiivsete finantsteenuste pakkumiseks Maaelu Edendamise Sihtasutuse juurde ariuhingu asutamisega seonduvate rahastamisvoimaluste analuusimine. Survey report. Tartu: Estonian University of Life-Sciences.

7. IESS. Institute of Economics and Social Sciences. (2017). Foresight Analysis on the Common Agricultural Policy - uhise pollumajanduspoliitika tulevikuanaluus. Final report. Tartu: Estonian University of LifeSciences. Eesti Konjunktuuriinstituut.

8. Liesivaara, P., Myyra, S. (2017). The Demand for Public-private Crop Insurance and Government Disaster Relief. Journal of Policy Modeling, Volume 39, Issue 1, pp. 19-34. 
9. Meuwissen, M.P.M., Huirne, R.B.M., Hardaker, J.B. (1999). Income Insurance in European Agriculture, Luxembourg: European Commission. Scientific Report EU-Project, European Economy, No. 2, DGII, Brussels, pp. 95

10. Nelson, C.H., Loehman, E.T. (1987). Further toward a Theory of Agricultural Insurance. American Journal of Agricultural Economics, Volume 69, No. 3, pp. 523-531

11. Schaper, C., Lassen, B., Theuvsen, L. (2009). Risk Management in Milk Production: A Study in Five European Countries. 113th EAAE Seminar "A resilient European food industry and food chain in a challenging world" Chania, Crete, Greece. Sept. 3-6, 2009.

12. SOE. Statistical Office of Estonia. (2018). AG042: Average Yields of Field Crops by Field Crop, County and Year. Online database. Retrieved: http://www.stat.ee/ Access: 01.02.18

13. Valverde Arias, O., Garrido, A., Villeta, M., Tarquis, A.M. (2018). Homogenisation of a Soil Properties Map by Principal Component Analysis to Define Index Agricultural insurance Policies. Conference: Pedometrics Conference Location: Univ Cordoba, Cordoba, SPAIN, Date: SEP 14-18, 2015. Geoderma, Volume 311, pp $149-158$

14. Van Asseldonk, M., Tzouramani, I., Ge, L. (2016). Adoption of Risk Management Strategies in European Agriculture. Studies in Agricultural Economics, Volume 118, Issue 3 pp. 154-162. 